\title{
PERANCANGAN APLIKASI PEMESANAN MENU MAKANAN DAN MINUMAN PADA CAFE DENGAN BERBASIS WEB
}

\author{
Kholik Setiawan $^{1)}$, Fauzi Yusa Rahman ${ }^{2)}$, Indu Indah Purnomo ${ }^{3)}$ \\ ${ }^{1)}$ Fakultas Teknologi Informasi, Universitas Islam Kalimantan MAB Banjarmasin \\ email: kholiksetiawanfti@gmail.com \\ ${ }^{2)}$ Fakultas Teknologi Informasi, Universitas Islam Kalimantan MAB Banjarmasin \\ email: fauziyusarahman@gmail.com \\ ${ }^{3)}$ Fakultas Teknologi Informasi, Universitas Islam Kalimantan MAB Banjarmasin \\ email: indumbc@gmail.com
}

\begin{abstract}
Abstrak
Fellas Coffe and Eatry merupakan salah satu usaha berbasis café yang beralamat di Pelaihari, Kalimantan Selatan. Fellas Coffe and Eatry menyediakan berbagai jenis makanan dan minuman. Pada saat ini pengelolaan data pelayanan Fellas Coffe and Eatry masih bersifat manual, ketersediaan tempat duduk bagi pelanggan, ketersediaan makanan dan minuman masih bersifat manual, yaitu pelanggan mencari tempat duduk kemudian melakukan pemesanan makanan dan minuman kepada pelayanan, dan pelayan melakukan pemberitahuan kepada bagian dapur tentang menu makanan dan minuman yang dipesan oleh pelanggan. Pada bagian dapur proses nya belum tertata secara baik dalam pengelolaan antrian pemesanan makanan dan minuman, maka terjadinya kesulitkan dalam melakukan proses pesanan. Hal seperti tentu saja memiliki berbagai kerungan-kekurangan, antara lain data ketersedian tempat duduk bagi pelaggan, ketersediaan makanan dan minuman yang nanti nya memperlampat proses pelayanan. Serta catatan pesanan pelanggan mugkin saja hilang dan rusak, bahkan kesulitan bagi juru masak yaitu bagaimana mengingat data pesanan menu dari pelanggan dan nomer meja pelanggan. Karena permasalahan itu maka peneliti membuat sebuah webite yang bisa dimanfaatkan dalam menyimpan semua data pelanggan yang akan memesan tempat maupun pelanggan yang memesan makanan dan minuman menggunakan metode jenis waterfall, karena metode jenis ini menggambarkan proses yang mudah dan memiliki urutan pada proses perkembangan perangkat lunak, proses dilakukan mulai dari kebutuhan sampai proses akhiri dengan hasil sebuah perangkat lunak.
\end{abstract}

Kata Kunci: Aplikasi, Web, Cafe, Pelayanan

\section{PENDAHULUAN}

Perkembangan pada teknologi informasi dan komunikasi, mendorong dalam proses persaingan bisnis. Pelaku dalam dunia bisnis melakukan persaing untuk mencari dan meraih pelanggan. Cafe merupakan salah satu jenis usaha dalam bidang penjualan berbagai jenis makanan dan berbagai jenis minuman. Pada saat ini pengelolaan data ketersediaan tempat duduk bagi pelanggan, ketersediaan makanan dan minuman masih bersifat manual, yaitu pelanggan mencari tempat duduk kemudian melakukan pemesanan makanan dan minuman kepada pelayanan, dan pelayan melakukan pemberitahuan kepada bagian dapur tentang menu makanan dan minuman yang dipesan oleh pelanggan. Pada bagian dapur proses nya belum tertata secara baik dalam pengelolaan antrian pemesanan makanan dan minuman, maka terjadinya kesulitkan dalam melakukan proses pesanan.

Hal seperti tentu saja memiliki berbagai kerungan-kekurangan, antara lain data ketersedian tempat duduk bagi pelaggan, ketersediaan makanan dan minuman yang 
nanti nya memperlampat proses pelayanan. Serta catatan pesanan pelanggan mugkin saja hilang dan rusak, bahkan kesulitan bagi juru masak yaitu bagaimana mengingat data pesanan menu dari pelanggan dan nomer meja pelanggan. Karena permasalahan itu maka peneliti membuat sebuah webite yang bisa dimanfaatkan dalam menyimpan semua data pelanggan yang akan memesan tempat maupun pelanggan yang memesan makanan dan minuman.

\section{METODE PENELITIAN}

Penerapan website pelayanan pada Fellas Coffe and Eatry menggunakan metode jenis waterfall atau biasa disebut dengan istilah classic life cycle, pada metode jenis ini menggambarkan proses yang mudah dan memiliki urutan pada proses perkembangan perangkat lunak.

Pada metode jenis waterfall memiliki beberapa proses dan memiliki tahapantahapan yang terurut antara lain: requirement analysis (analisis kebutuhan), design (desain), coding (penulisan kode) dan testing (pengujian), dan maintenance (pemeliharaan).

\subsection{Pegumpulan Data}

Proses yang akan dilakukan dalam pengumpulan data dilakukan dengan dua jenis cara yaitu:

1. Pengumpulan data yang bersifat primer, melakukan survei ke lapangan sesuai dengan kebutuhan data.

2. Pengumpulan data yang bersifat sekunder, data dikumpulkan dan diamati kemudian mempelajari data tersebut.

Langkah-langkah yang akan diterapkan dalam menyelesaikan penelitian, yaitu:

\section{Studi literatur}

Tahapan studi kiteratur dilakukan dengan cara mencari literatur dengan rincian sebagai berikut:
a. Referensi mengenai permasalahan pada aplikasi terkait.

b. Mencari permasalahan yang biasa ditemui dan mencari solusi permasalahan.

\section{Analisa Sistem}

Pada tahapan analisa sistem penulis melakukan analisa masalah, keperluan dalam sistem, dan mencari solusi dari analisa yang akan dilakukan.

\section{Perancangan Sistem}

Pada tahapan perancangan sistem penulis melakukan perancangan sesuai dengan hasil dari analisa dan dilanjutkan dengan implementasi hasil analisa menjadi sebuah sistem.

\section{Pengujian}

Pada tahapan pengujian penulis melakukan pengujian terhadap sistem apakah sesuai dengan perancangan yang sudah dibuat sebelumnya.

\section{Penyusunan laporan}

Pada tahapan peyusunan laporan penulis melakukan penulisan dokumentasi dari hasil sistem dalam bentuk laporan penelitian.

\subsection{TahapPenelitian}

Tahapan-tahapan dari penelitian yang dilakukan dalam mebuat website pelayanan pada Fellas Coffe and Eatry, yaitu:

1. Pengajuan proposal dalam penelitian

2. Penentuan objek dalam penelitian

3. Kajian teori dalam menetukan rancangan

4. Pengumpulan data primer dan sekunder

5. Pegolahan data

6. Pembuatan sistem

7. Pengujian sistem

8. Pembuatan laporan

9. Seminar hasil penelitian, menguraikan jenis metode telah digunakan meliputi tahapan-tahapan dalam penelitian, lokasi tempat dilaksanakan penelitian, perubahan-perubahan yang akan di amati, perancangan dalam penelitian serta teknik pegumpulan data dan bahagaimana hasil dari analisis data. 
Penelitian yang dilakukan dengan menggunakan metode kualitatif parlu dijelaskan cara pendekatan yang digunakan, bagaimana proses pengumpulan data, bagaimana proses analisis informasi, serta dilakukan penafsiran dan kesimpulan dari hasil penelitian yang sudah dilaksanakan.

\subsection{Testing}

Pada tahapan testing pada aplikasi, dilakukan percobaan terhadap aplikasi berbasis website yang selesai dikerjakan dengan menggunakan modem dan satu buah komputer sebagai server, setiap proses pada website dilakukan percobaa dalam hal proses data sebelum di lakukan hosting ke server yang telah disediakan.

\subsection{Lokasi dan Waktu Penelitian}

Lokasi penelitian dilaksanankana pada Fellas Coffe and Eatry yang beralamat di Pelaihari, Kalimantan Selatan. Sedangkan waktu dalam penelitian berlangsung selama empat bulan sejak persiapan hingga penyusunan laporan

\section{HASIL DAN PEMBAHASAN}

Website pelayanan pada Fellas Coffe and Eatry terdiri dari atas tiga level pengguna, yaitu administrator yang berfungsi mengelola webiste, kasir yang berfungsi dalam pemesanan makanan dan minuman, dan pelanggan. Website pada pelayanan cafe bisa di pakai secara offline maupun online.

\subsection{Perancangan Basis Data}

Perancangan basis data pada website digunakan oleh peneliti untuk menentukan kebutuhan tabel yang akan digunakan. Perancangan database pada website pelayanan cafe menggunakan basis data yaitu MySQL pada halaman PHPMyAdmin dan kemudian di beri nama caffe, berikut adalah berbagai tabel-tabel yang terbentuk, antara lain:
1. booking_meja

2. $\operatorname{login}$

3. makanan_minuman

4. master_meja

\subsection{Diagram Konteks}

Diagram konteks merupakan proses untuk melihat proses dari sistem yang akan dikembangkan, dari mana dan mau kemana data dikelola. Berikut perancangan dari diagram konteks yang terbentuk dalam aplikasi yang dikembangkan:

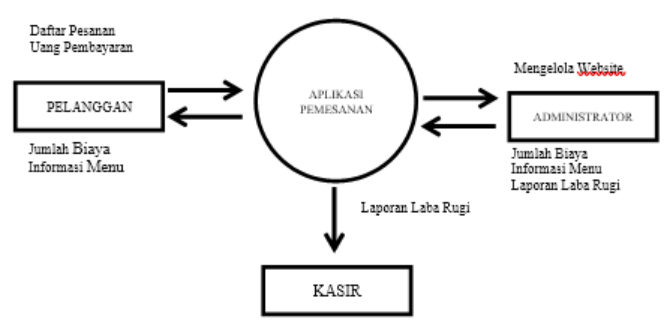

Gambar 1. Diagram Konteks

\subsection{Rancangan Tampilan}

Rancangan tampilan merupakan hasil dari website cafe yang sudah di buat, berikut tampilan yang dibuat:

1. Tampilan Login

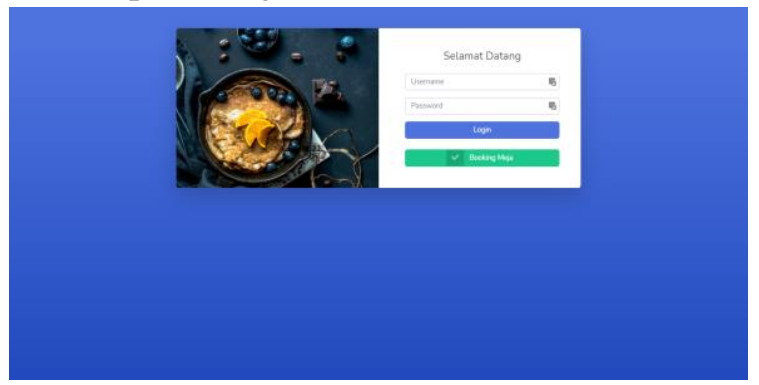

Gambar 2. Tampilan login

2. Tampilan Dashboard Awal 


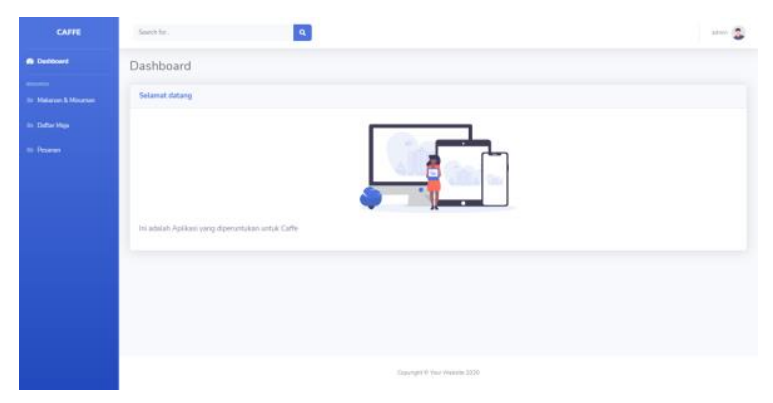

Gambar 3. Tampilan Dashboard awal

\section{Tampilan List makanan dan minuman}
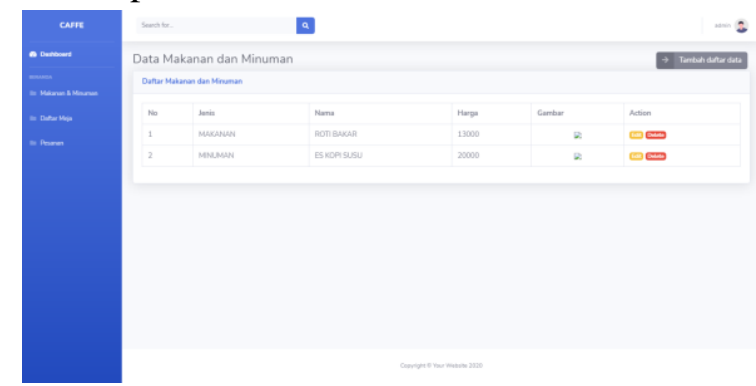

Gambar 4. Tampilan List makanan dan minuman

4. Tampilan Tambah menu makanan dan minuman

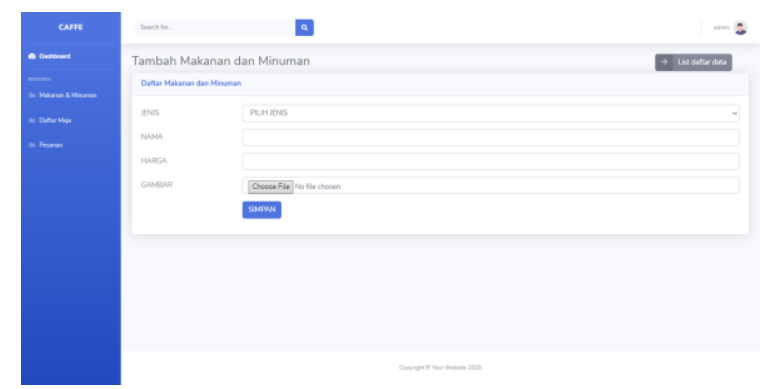

Gambar 5. Tampilan Tambah menu makanan dan minuman

\section{Tampilan List Meja}

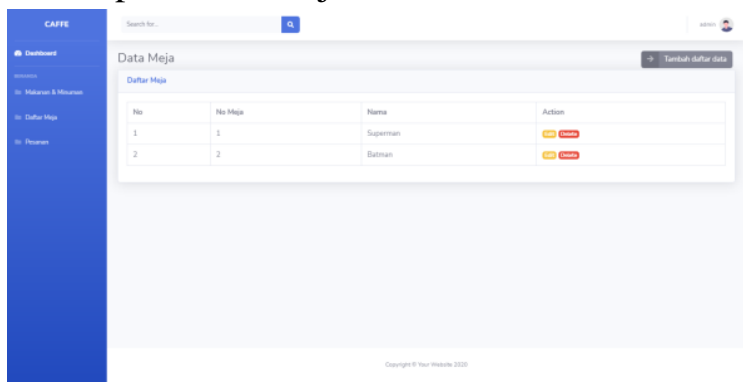

Gambar 6. Tampilan List meja
6. Tampilan Tambah data meja

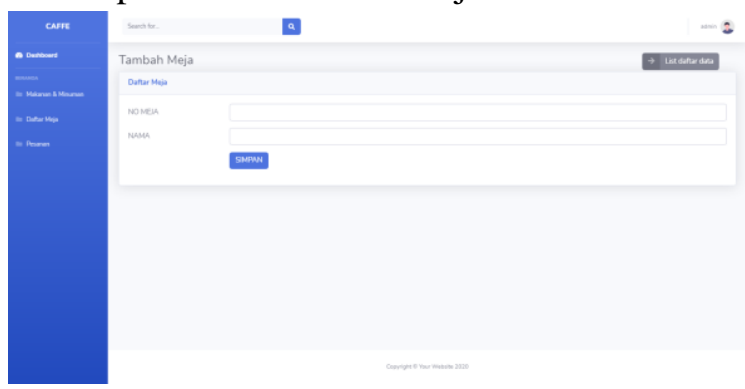

Gambar 7. Tampilan Tambah data meja

\section{Tampilan List booking meja}

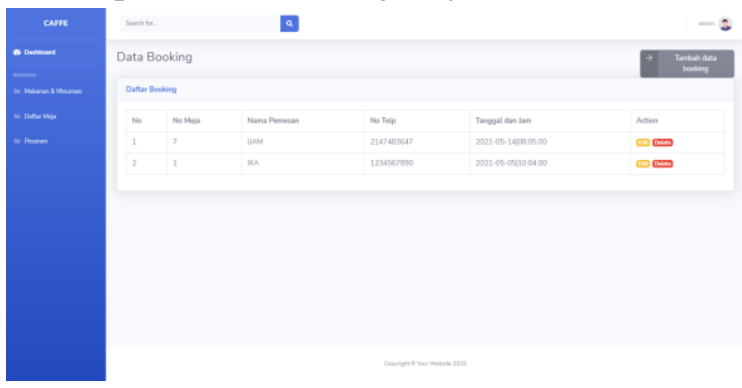

Gambar 8. Tampilan List booking meja

8. Tampilan Tambah booking meja

a

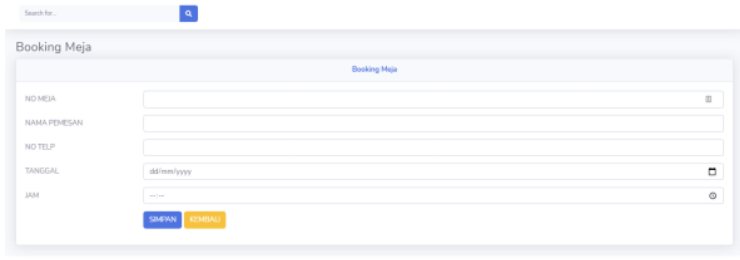

Gambar 9. Tampilan Tambah booking meja

\section{KESIMPULAN}

Penelitian dilakukan pada Fellas Coffe and Eatry yang beralamatkan di Pelaihari, Tanah laut, Kalimantan Selatan. Fellas Coffe and Eatry mejual makanan dan minuman yang mengikuti tren masa kini yaitu mengusung konsep caffe modern. Penelitian ini bertujuan untuk memudahkan caffe sejenis men-data meja, makanan dan minuman yang tersedia di caffe tersebut, dan sebagai tambahan adanya menu booking meja agar memudahkan pelanggan atau 
konsumen untuk datang. Karena saat tanggal merah ataupun weekend sering terjadinya pelanggan yang datang terlalu banyak sehingga pelanggan tersebut tidak mendapatkan meja, dengan adanya menu booking ini maka hal tersebut dapat diminimalisir dengan menu booking tersebut. Website pelayanan Fellas Coffe and Eatry menggunakan metode waterfall, metode jenis ini menggambarkan proses yang mudah dan memiliki urutan pada proses perkembangan perangkat lunak, proses dilakukan mulai dari kebutuhan dari pengguna berlanjut melalui tahapan perencanaan, tahapan permodelan, tahapan konstruksi, kemudian dilakukan tahapan penyerahan sistem ke pengguna akhir, kemudian tahapan pada proses diakhiri dengan proses perangkat lunak yang dihasilkan.

\section{DAFTAR PUSTAKA}

[1] Defrina, D., \& Lestari, D. P. 2017. Aplikasi Pemesanan Makanan dan Minuman Online Berbasis Mobile Browser pada Restoran Tiga Saudara. Jurnal Ilmiah Informatika dan Komputer Vol. 22 No. 3, 158-170.

[2] Martono. (2018). Pembuatan Aplikasi EMenu (Electronic Menu) Berbasis Website Dan Android. Jurnal Ilmiah Media Sisfo Vol. 12, No.1.

[3] Immah Inayanti. (2015). Aplikasi Pemesanan Makanan dan Minuman. Jurnal Naradoid Vol. 1, No.2.

[4] Peranginangin, K. (2006). Aplikasi WEB dengan PHP dan MySQL. Yogyakarta: ANDI.

[5] Wikipedia. (2020, Desember 1). HTML. Retrieved Desember 1, 2020, dari Wikipedia: https://id.wikipedia.org/wiki/HTML

[6] Wikipedia. (2020, Desember 1). PHP. Retrieved Desember 1, 2020, dari Wikipedia: https://id.wikipedia.org/wiki/PHP 